\title{
Molecular Characterization of Spider Plant (Cleome gynandra) Accessions Using SSR Markers
}

\author{
Fhatuwani Thovhogi ${ }^{1, *}$, Eastonce T. Gwata ${ }^{1}$, Godwin R. A. Mchau ${ }^{1}$, Sieyaam S. Safodien ${ }^{2}$ \\ and Trevor Koopman 2 (D) \\ 1 Department of Plant and Soil Sciences, University of Venda, P. Bag X5050, Thohoyandou 0950, South Africa; \\ ectgwata@gmail.com (E.T.G.); ainamensa.mchau@univen.ac.za (G.R.A.M.) \\ 2 Agricultural Research Council Infruitec-Nietvoorbij, Institute of Deciduous Fruit, Private Bag X5026, \\ Stellenbosch 7599, South Africa; SafodienS@arc.agric.za (S.S.S.); KoopmanT@arc.agric.za (T.K.) \\ * Correspondence: Fhatuwani.thovhogi@univen.ac.za
}

Citation: Thovhogi, F.; Gwata, E.T.; Mchau, G.R.A.; Safodien, S.S.; Koopman, T. Molecular Characterization of Spider Plant (Cleome gynandra) Accessions Using SSR Markers. Agronomy 2021, 11, 2206. https://doi.org/10.3390/ agronomy11112206

Received: 13 September 2021

Accepted: 18 October 2021

Published: 30 October 2021

Publisher's Note: MDPI stays neutral with regard to jurisdictional claims in published maps and institutional affiliations.

Copyright: (c) 2021 by the authors. Licensee MDPI, Basel, Switzerland. This article is an open access article distributed under the terms and conditions of the Creative Commons Attribution (CC BY) license (https:// creativecommons.org/licenses/by/ $4.0 /)$.

\begin{abstract}
Spider plant (Cleome gynandra L.) is an indigenous leafy vegetable that is a rich source of minerals, proteins, vitamins, flavonoids, antioxidants and many other compounds. Morphological characterization of the germplasm for optimal genetic exploitation is limited by environmental factors. The objective of this study was to determine the degree of genetic diversity between exotic and local spider plant accessions using molecular markers. The spider plant germplasm consisted of 18 local and exotic accessions. Seven polymorphic simple sequence repeat (SSR) markers were used in the study. The SSR marker combinations revealed a total of 46 alleles at 7 loci, with an average of 6.57 alleles per locus. An average polymorphic information index of 0.69 was recorded. According to Nei's genetic distance analysis, low population differentiation was observed between the local and exotic spider plant accessions, which was indicated by a low fixation index value of 0.024 and a high $\mathrm{Nm}$ (10.20). Analysis of molecular variance showed no significant $(p<0.327)$ variation among and within the local and exotic accessions. Furthermore, low population differentiation was recorded when accessions were grouped based on their stem colour, with an Fst value of 0.007. In both the hierarchical clustering using an unweighted pair group method with arithmetic mean (UPGMA) and principal coordinate analysis (PCoA), the local accession 'ML-3-KK' was grouped alone, suggesting that this accession was different from the rest of the accessions and could be useful in selection programmes for spider plant genetic improvement. Both the UPGMA and PCoA were similar in clustering the eighteen spider plant accessions into four groups. The local spider plant accessions were more genetically diverse (with sixteen rare alleles) when compared to the exotic accessions (with only three rare alleles). The rare alleles provided useful information on the genetic variability in certain loci and identification of accessions that could be used as parental lines in spider plant breeding programmes.
\end{abstract}

Keywords: accession; allele; cluster; genetic diversity; microsatellite

\section{Introduction}

Spider plant (Cleome gynandra L.) is an important indigenous leafy vegetable in SubSaharan Africa. It is an excellent source of minerals, proteins, vitamins, flavonoids, antioxidants and many other compounds [1-3]. This vegetable is increasingly becoming a popular vegetable and a cash crop in some parts of Africa, such as Kenya [4-6]. In South Africa, the spider plant is collected from the wild [7]. This vegetable contributes to food security and mitigation of micronutrient deficiencies [1]. Despite its importance, there is limited information on the extent and structure of genetic variation and the potential for crop improvement by domestication, selection and breeding of spider plant $[8,9]$.

Genetic diversity is the source for crop improvement and germplasm conservation $[10,11]$. Therefore, it offers plant breeders an opportunity to develop new and improved cultivars with desirable characteristics [11]. Genetic diversity between and within 
species can be assessed by morphological characterization, biochemical evaluation, and molecular marker analysis [11-13]. Studies on the morphological characterization of spider plant have been conducted in Kenya and Zimbabwe [1,14-16].

Morphological characters can be influenced by environmental factors while molecular markers are not. Furthermore, molecular makers have been extensively used in many crops to explain the structure of genetic diversity [17]. Therefore, measuring genetic diversity by molecular analysis is one of the best options for distinguishing more accurately between genotypes $[10,12]$. There are limited studies conducted on the genetic variation of different indigenous leafy vegetables using molecular markers. Previous studies used molecular markers such as simple sequence repeat (SSR) and amplified fragment length polymorphisms (AFLPs) on indigenous leafy vegetables [10]. The extent of genetic diversity and the relationship between 32 cowpea (Vigna ungiiculata L.) genotypes from the Iranian germplasm using SSR markers was investigated [18]. Random amplified polymorphic DNA (RAPD) markers were used in a study involving the diversity of Solanum species [19] and several other species [20-24].

However, limited work was carried out on the genetic diversity of spider plant using molecular markers. Genetic variation in four spider plant morphotypes from Kenya were assessed using random amplified polymorphic DNA polymerase chain reaction (RAPDPCR) technology and the morphotypes were grouped into three clusters according to the colour of the stem and petiole [25]. Ten polymorphic inter simple sequence repeat (ISSR) markers were used to determine the level and organization of spider plant germplasm in Burkina Faso [26]. Furthermore, genetic variations of spider plant from different countries were investigated using 11 AFLP primer combinations and nine SSR makers [27]. The main objective of this study was to determine the genetic diversity among local and exotic germplasm of spider plant using SSR markers.

\section{Materials and Methods}

\subsection{Plant Material}

Eighteen accessions of spider plant were used (Table 1). The accessions were obtained from Limpopo, Mpumalanga and Arusha, Tanzania. The accessions possessed some distinct morphological features (Table 2) - particularly stem colour (Figure 1). The leaves were harvested from 4-week-old plants that were raised in $5 \mathrm{~L}$ plastic bags in a shadehouse at the University of Venda experimental farm and placed in separate Ziploc polybags in a cooler box, and transferred to the Agricultural Research Council (ARC) InfrutecNiietvoorbij Stellenbosch for molecular analysis.

\subsection{DNA Extraction}

Genomic DNA was extracted using the cetyl trimethylammonium bromide (CTAB) method according to $[25,28]$. Extraction reagents of $2 \mathrm{~mL}$ pre-warmed $\left(65^{\circ} \mathrm{C}\right) \mathrm{CTAB}$ buffer [3\% $(m / v)$ CTAB (Merck (Pty) Ltd., Modderfontein, South Africa), 1\% $(m / v)$ PVP 40 (SigmaAldrich (Merck), St. Louis, MO, USA), 2.0M NaCl (Merck (Pty) Ltd., Modderfontein, South Africa), 20 mM EDTA pH 8 (Merck (Pty) Ltd., Modderfontein, South Africa), $100 \mathrm{mM}$ Tris $\mathrm{pH} 8$ (Melford Laboratories, Chelsworth, Ipswich, UK)] and $0.01 \mathrm{~mL} \beta$-mercaptoethanol (Merck (Pty) Ltd., Modderfontein, South Africa) were added. A fresh extraction buffer of CTAB and $1 \%$ (0.5 g in $50 \mathrm{~mL}$ ) PVP-40 (polyvinylpyrrolidone) was prepared before extraction. Polyvinylpyrrolidone was added to the extraction buffer to prevent browning due to high polyphenols and other secondary metabolites like flavonoids [29]. Leaf samples (each weighing $0.5 \mathrm{~g}$ ) were ground to a fine powder using liquid nitrogen and a mortar and pestle. Immediately after thawing the samples, $2 \mathrm{~mL}$ of pre-heated extraction buffer was added to leaf material and further ground into a slurry. The homogenate was transferred to $2 \mathrm{~mL}$ Eppendorf tubes while working in a fume hood and $10 \mu \mathrm{L} \beta$-mercaptoethanol was added and mixed by gentle inversion. The tubes were incubated for $1 \mathrm{~h}$ at $60^{\circ} \mathrm{C}$. An equal volume of $1 \mathrm{~mL}$ chloroform-isoamyl alcohol (Merck (Pty) Ltd., Modderfontein, South Africa) at a ratio of 24:1 was added to the homogenate and mixed by gentle inversion. The 
tubes were centrifuged at 13,000 rpm for $15 \mathrm{~min}$ prior to transferring the upper aqueous phase into a fresh $2 \mathrm{~mL}$ Eppendorf tube and five microliters RNase A $(10 \mathrm{mg} / \mathrm{mL})$ was added to each tube followed by incubation for $30 \mathrm{~min}$ at $37^{\circ} \mathrm{C}$. An equal volume of $1 \mathrm{~mL}$ chloroform-isoamyl alcohol (24:1) was added to each tube and mixed by gentle inversion. The tubes were centrifuged again at 13,000 rpm for $15 \mathrm{~min}$. The top aqueous phase was then recovered and precipitated with $0.8 \mathrm{~mL}$ isopropanol (Merck (Pty) Ltd., Modderfontein, South Africa) and centrifuged at 13,000 rpm for $15 \mathrm{~min}$. The solution was discarded, and the pellets were washed with $70 \%$ ethanol (cold) and centrifuged at $4{ }^{\circ} \mathrm{C}$ for $10 \mathrm{~min}$ at $13,000 \mathrm{rpm}$. The pellets were dried for an hour and re-suspended in $200 \mathrm{~mL}$ sterile $1 \times \mathrm{TE}$ buffer (10 Mm Tris-Cl pH 8.0; $0.1 \mathrm{mM}$ EDTA) and stored at $4{ }^{\circ} \mathrm{C}$ until further use.

Table 1. Origins of the spider plant accessions that were used in this study.

\begin{tabular}{ccc}
\hline Code/Name & Origin & Classification \\
\hline 1. ML-2-DD & Limpopo Province (South Africa) & Local \\
2. ML-3-KK & Limpopo Province (South Africa) & Local \\
3. ML-5-TGM & Limpopo Province (South Africa) & Local \\
4. ML-12-TMP & Limpopo Province (South Africa) & Local \\
5. ML-13-SDM & Limpopo Province (South Africa) & Local \\
6. ML-14-MAG & Limpopo Province (South Africa) & Local \\
7. ML-6-BTK & Limpopo Province (South Africa) & Local \\
8. ML-15-ITN & Limpopo Province (South Africa) & Local \\
9. MP-B-1-CG & Mpumalanga Province (South Africa) & Local \\
10. MP-B-2-CG & Mpumalanga Province (South Africa) & Local \\
11. MP-B-3-CG & Mpumalanga Province (South Africa) & Local \\
12. MP-B-4-CG & Mpumalanga Province (South Africa) & Local \\
13. TZ-1 & Tanzania Local seed & Exotic \\
14. IP-3 & Kenya (WorldVeg, Tanzania, Arusha) & Exotic \\
15. ML-SF-29 & Malawi (WorldVeg, Tanzania, Arusha) & Exotic \\
16. PS & Tanzania (WorldVeg, Tanzania, Arusha) & Exotic \\
17. GPS & Tanzania (WorldVeg, Tanzania, Arusha) & Exotic \\
18. UG-SF-15 & Uganda (WorldVeg, Tanzania, Arusha) & Exotic \\
\hline Exotic accession = accession originating in a foreign country. WorldVeg = World Vegetable Center.
\end{tabular}

Table 2. Qualitative morphological characters of the local and exotic spider plant accessions that were used in the study.

\begin{tabular}{ccccc}
\hline \multirow{2}{*}{ Morphological Character } & \multicolumn{2}{c}{ Percentage of Accessions (\%) } \\
\cline { 3 - 5 } & & All & Local & Exotic \\
\hline \multirow{3}{*}{ 1. Stem colour } & (a) Green & 36.4 & 36.4 & 36.5 \\
& (b) Purple & 60.2 & 60.7 & 59.2 \\
& (c) Green-purple & 3.4 & 2.9 & 4.3 \\
\hline \multirow{3}{*}{ 2. Flower colour } & (a) White & 25.4 & 27.6 & 21 \\
& (b) Cream & 66 & 63.8 & 70.5 \\
& (c) Purple & 0.9 & 6.4 & 8.6 \\
3. Petiole colour & (d) Pink & 0.5 & 1.4 & 0 \\
& (e) Mixture & 0 & 0.7 & 0 \\
\hline \multirow{3}{*}{ 4. Stem pubescence } & (a) Green & 58.4 & 58 & 59.1 \\
& (b) Purple & 18.8 & 19.4 & 17.6 \\
& (c) Green tinged with purple & 20.3 & 20.5 & 19.8 \\
& (d) Purple tinged with green & 2.4 & 2.1 & 2.9 \\
\hline \multirow{2}{*}{ 5. Pod colour } & (a) None & 6.7 & 5.5 & 9.1 \\
& (b) Sparse & 27.3 & 28.1 & 25.8 \\
& (c) Intermediate & 24.8 & 26.9 & 20.5 \\
& (d) Abundant & 41.2 & 39.5 & 44.6 \\
\hline
\end{tabular}



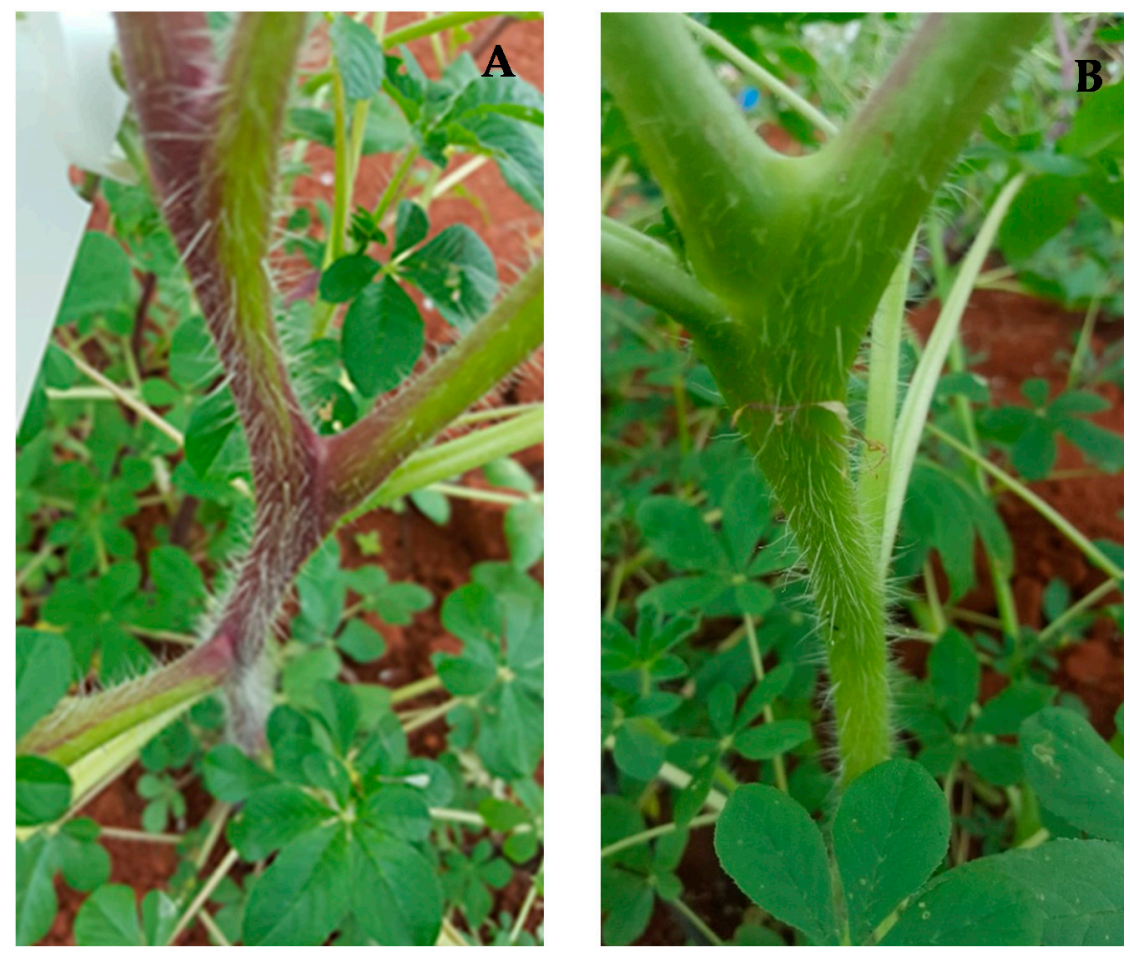

Figure 1. An example of variation in stem colour $((\mathbf{A})=$ purple and $(\mathbf{B})=$ green $)$ among the accessions

The quality and quantity of the DNA was determined with a BioDrop DUO (Biochrom Ltd., Cambridge, UK), for measurement of micro-volume samples following the manufacturer's instructions. If a sample showed poor quality and quantity of DNA, the extraction was repeated. The extracted DNA samples from the different accessions were diluted and adjusted to a final concentration of $100 \mathrm{ng} / \mu \mathrm{L}$ prior to storage at $-20{ }^{\circ} \mathrm{C}$ to avoid deterioration.

\subsection{Simple Sequence Repeat Analysis and PCR Optimization}

Nine SSR primers (Table 3) designed through next-generation sequencing of the genomic DNA from spider plant were selected as these primers were polymorphic and gave products of the expected size [27]. The forward primers were fluorescently labelled with dyes (Applied Biosystems, Foster City, CA, USA) [27]. The reverse primers (Applied Biosystem, Foster City, CA, USA) were unlabeled. Each forward primer was tailed with the universal M13 primer at the $5^{\prime}$ end and a FAM-labelled M13 primer included for a two-step PCR [30]. All primers, including the unlabeled reverse primer, were purchased from IDT (Whitehead Scientific (Pty) Ltd., Cape Town, South Africa). All primers were dissolved in sterile TE buffer (10 mM Tris-Cl, $\mathrm{pH} 8.0 ; 1 \mathrm{mM}$ EDTA) to obtain a stock concentration of $100 \mu \mathrm{M}$. Each primer was then prepared as a $10 \mu \mathrm{M}$ working stock. The fluorescent-labelled primer (M13-FAM) was kept in the dark all the time.

\subsection{Microsatellite Genotyping}

After some PCR optimization, all PCR reactions were performed in $20 \mu \mathrm{L}$ volumes containing $2.0 \mathrm{mM} \mathrm{MgCl} 2,0.2 \mathrm{mM}$ dNTPs, $0.25 \mu \mathrm{M}$ of the forward primer, $1.0 \mu \mathrm{M}$ of the reverse primer, $1.0 \mu \mathrm{M}$ of the FAM-labelled M13 primer, 1.0 U GoTaq Flexi (Anatech Instruments (Pty) Ltd., Cape Town, South Africa) and 30 ng genomic DNA. Reactions were carried out on a GeneAmp PCR system 9700 (Applied Biosystems, Foster City, CA, USA) using the following PCR conditions: an initial denaturation step of $5 \mathrm{~min}$ at $94{ }^{\circ} \mathrm{C}, 25$ cycles of $45 \mathrm{~s}$ at $94{ }^{\circ} \mathrm{C}, 1 \mathrm{~min}$ at the appropriate annealing temperature for the particular primer pair and $1 \mathrm{~min}$ at $72{ }^{\circ} \mathrm{C}$, followed by 8 cycles of $30 \mathrm{~s}$ at $94{ }^{\circ} \mathrm{C}, 45 \mathrm{~s}$ at $52^{\circ} \mathrm{C}, 1 \mathrm{~min}$ at $72{ }^{\circ} \mathrm{C}$, and a final extension of $10 \mathrm{~min}$ at $72^{\circ} \mathrm{C}$. Fragment analyses were performed on an Applied Biosystems ABI3730 DNA analyser using a LIZ-500 (-250) size standard at the Central 
Analytical Facility, University of Stellenbosch. Allele sizes were subsequently assessed and scored using GeneMapper version 5.0 (Applied Biosystems, Foster City, CA, USA).

Table 3. Microsatellite primer sequence and core motif used in the analysis, allele size range and number of alleles for local and exotic spider plant accessions.

\begin{tabular}{|c|c|c|c|c|c|}
\hline Locus & Forward Sequence & Core Motif & Reported Size (bp) & Allele Size Range (bp) & No. of Alleles \\
\hline CG001 & $\begin{array}{c}\text { F: TGT AAA ACG ACG GCC AGT } \\
\text { CGTCAGTAGCATTTGGTTCG } \\
\text { R: TTCCAATACAAAGGGTGACAAC }\end{array}$ & (AG) 20 & 215 & $184-230$ & 19 \\
\hline CG017 & $\begin{array}{c}\text { F: TGT AAA ACG ACG GCC } \\
\text { AGTTTTGAAGTGGCAACAGCGTA } \\
\text { R: AATGGATTTGGTTCATGTGG }\end{array}$ & (AACCCTA) 5 & 205 & $199-245$ & 14 \\
\hline CG018 & $\begin{array}{c}\text { F: TGT AAA ACG ACG GCC } \\
\text { AGTCGAAATGCTTCACTTGCTCA } \\
\text { R: CCTTCTTCATTCCCAAACGA }\end{array}$ & $(\mathrm{AACCCT}) 6$ & 276 & $276-293$ & 8 \\
\hline CG022 & $\begin{array}{c}\text { F: TGT AAA ACG ACG GCC } \\
\text { AGTATGGGCTTTCCGTTTTTCAT } \\
\text { R: CGCTTCCATGGACTGGTAAT }\end{array}$ & (CAACAC) 7 & 227 & $212-243$ & 9 \\
\hline CG024 & $\begin{array}{l}\text { F: TGT AAA ACG ACG GCC } \\
\text { AGTGGATGCAATTGTACAGCTCG } \\
\text { R: ATGGCGTATGGGTTGAAGAT }\end{array}$ & (TTGTGACCT) 4 & 254 & $245-272$ & 10 \\
\hline CGO27 & $\begin{array}{l}\text { F: TGT AAA ACG ACG GCC } \\
\text { AGTATATTTGTGTGGGGTGGCTG } \\
\text { R: ATTGGAGGCAAACGAATGAG }\end{array}$ & (GAATGCTT) 3 & 200 & $179-210$ & 6 \\
\hline CG028 & $\begin{array}{c}\text { F: TGT AAA ACG ACG GCC } \\
\text { AGTACCTTCGTTTTTGTTGTCGG } \\
\text { R: ATCAATTCTCCTGCGCAAAC }\end{array}$ & (TAGAATTT) 3 & 270 & - & - \\
\hline CG032 & $\begin{array}{c}\text { F: TGT AAA ACG ACG GCC } \\
\text { AGTGGGCCTGCAAAAACAAATAA } \\
\text { R: TGGACAGATTTTCTGGTGGA }\end{array}$ & (AGACC) 7 & 221 & - & - \\
\hline CG033 & $\begin{array}{c}\text { F: TGT AAA ACG ACG GCC } \\
\text { AGTCCTTAACGATCACGCATTCA } \\
\text { R: CTCAACGTTCCACCTCCAAC }\end{array}$ & (ATATA) 8 & 184 & $182-217$ & 11 \\
\hline M13 & $\begin{array}{l}\text { FAM-TGT AAA ACG ACG GCC AGT } \\
\text { (LABELED WITH FAM) }\end{array}$ & & & & \\
\hline
\end{tabular}

\subsection{Statistical Analysis}

Genetic diversity parameters were calculated, firstly for the 18 accessions. The number of alleles per locus $(\mathrm{Na})$, observed heterozygosity $(\mathrm{Ho})$, expected heterozygosity $(\mathrm{He})$ and Shannon's information index (I) were calculated using GenAlEx version 6.51b2 [31]. The number of alleles per locus $(\mathrm{Na})$ is a direct count of alleles amplified by a given marker for all the samples. The observed heterozygosity (Ho) is the proportion of samples that are heterozygous and is obtained by dividing the number of heterozygous samples by the total number of samples evaluated. The expected heterozygosity $(\mathrm{He})$ for each marker was calculated on the basis of the formula by [32], $\mathrm{He}=1-\Sigma(\mathrm{pi})^{2}$, and pi is the probability that two alleles from the same locus are different when chosen at random from a given population. The polymorphic information content (PIC) of markers, PIC $=1-\Sigma(\text { pij) })^{2}$, was calculated using Gen-CALC software [33] to determine how informative the markers were. The analysis of molecular variance was calculated using GenAlEx version 6.51b2 [31].

Polymorphism was treated as binary data (presence or absence). Analysis of molecular variance and population differentiation (FST) were conducted to determine whether the populations were genetically different from each other (GenAlEx 6.5b2). The dissimilarity matrix using the Jaccard index was generated using binary data [34]. The microsatellite data was converted into binary using GenAlEx 6.51b2. Cluster analysis was performed using the unweighted pair group method (UPGMA) using XLSTAT 2020.5.1.1047. The genetic structure was determined by studying the number of private alleles for the local and exotic spider plant accessions. In GenAlEx 6.51b2 [31], principal coordinates analysis (PCoA) was carried out using the genetic distance matrix.

\section{Results}

\subsection{Marker Performance and Microsatellite Allelic Diversity}

Two (CG028 and CG032) of the nine markers used amplified unsatisfactorily, resulting in null alleles. In a previous study, these two markers amplified well, with a polymorphic 
information content (PIC) of 0.62 and 0.66 , respectively [27]. The remainder of the markers (CG001, CG017, CG018, CG022, CG024, CG027 and CG033) amplified well, with one or two clear peaks per sample that were interpreted as alleles. These seven markers were polymorphic across the 18 spider plant accessions. A total of 46 alleles were detected (Table 4), with an average of 6.57 alleles per locus. Three of the seven loci had null alleles (Table 4). Two local accessions 'ML-15-ITN', 'MP-B-3-CG' and one exotic accession 'IP-3' exhibited null alleles in three of the markers. Two dominant alleles were observed in markers CG018 and CG022. In markers CG027 and CG033, dominant alleles with allele frequencies of $50 \%$ and $47 \%$ were observed, respectively. At least three alleles at each locus were recorded in this study.

Table 4. Allelic variation of the microsatellite markers used for genotyping 18 spider plant accessions.

\begin{tabular}{|c|c|c|c|c|c|c|}
\hline \multirow[t]{2}{*}{ SSR } & \multirow[t]{2}{*}{ Alleles } & \multicolumn{2}{|c|}{ Allele Size (bp) } & \multirow{2}{*}{ Accessions with Null Alleles } & \multicolumn{2}{|c|}{ Predominating Allele } \\
\hline & & Min & Max & & Size (bp) & Frequency $(\%)$ \\
\hline CG001 & 11 & 184 & 230 & 2 & 207 & 22 \\
\hline CG017 & 9 & 199 & 245 & 1 & 227 & 32 \\
\hline CG018 & 4 & 276 & 293 & 1 & 287,293 & 32 \\
\hline CG022 & 6 & 212 & 243 & 0 & $220 / 225$ & 40 \\
\hline CG024 & 6 & 245 & 272 & 0 & 263 & 36 \\
\hline CG027 & 3 & 179 & 210 & 0 & 179 & 50 \\
\hline CG033 & 7 & 182 & 217 & 0 & 187 & 47 \\
\hline Total & 46 & & & 4 & & \\
\hline Mean & 6.57 & & & 0.57 & & \\
\hline
\end{tabular}

The number of effective alleles ranged from 2.67 to 7.53 for CG001, with an average of 4.18 alleles per locus (Table 5). The number of effective alleles per locus was smaller when compared with the observed number of alleles in the corresponding locus, except for CG018 and CG027. The heterozygosity revealed by the SSR markers ranged from 0.63 (for marker CG027) to 0.87 (for marker CG001). Shannon's Information Index of diversity values ranged from 1.04 (for marker CG027) to 2.19 (for marker CG001) while the observed heterozygosity ranged from 0.89 (for CG024 and CG033) to 1.00 (for CG001, CG017, CG018 and CG027). The PIC value ranged from 0.55 to 0.86 .

Table 5. Genetic diversity parameters generated by simple sequence repeat markers among 18 spider plant accessions.

\begin{tabular}{cccccccc}
\hline Locus & Na & Ne & I & Ho & He & F & PIC \\
\hline CG001 & 11.00 & 7.76 & 2.19 & 1.00 & 0.87 & -0.15 & 0.86 \\
CG017 & 9.00 & 5.35 & 1.90 & 1.00 & 0.81 & -0.23 & 0.79 \\
CG018 & 4.00 & 3.59 & 1.32 & 1.00 & 0.72 & -0.39 & 0.67 \\
CG022 & 6.00 & 2.97 & 1.30 & 0.94 & 0.66 & -0.42 & 0.60 \\
CG024 & 6.00 & 3.64 & 1.43 & 0.89 & 0.73 & -0.23 & 0.68 \\
CG027 & 3.00 & 2.67 & 1.04 & 1.00 & 0.63 & -0.60 & 0.55 \\
CG033 & 7.00 & 3.27 & 1.47 & 0.89 & 0.69 & -0.28 & 0.65 \\
\hline Mean & 6.57 & 4.18 & 1.52 & 0.96 & 0.73 & -0.33 & 0.69 \\
SE & 1.04 & 0.68 & 0.15 & 0.02 & 0.03 & 0.06 & 0.04
\end{tabular}

$\mathrm{Na}=$ number of alleles per locus, $\mathrm{Ne}=$ number of effective alleles per locus; I = Shannon's information index $\mathrm{Ho}=$ observed heterozygosity; $\mathrm{He}=$ expected heterozygosity; $\mathrm{F}=$ fixation index; $\mathrm{PIC}=$ polymorphic information index; $\mathrm{SE}=$ standard error.

\subsection{Differentiation between the Genetic Groups}

The Nei's unbiased genetic diversity measurements showed the lowest genetic distance was 0.120 and the highest genetic distance was 0.887 between exotic and local spider plant accessions (Table 6). Low genetic differentiation was observed (Fst $=0.024$ ) between the exotic and the local spider plant accessions. 
Table 6. Nei's unbiased measures of genetic identity (above diagonal) and genetic distance (below diagonal) calculated for exotic and local spider plant accessions.

\begin{tabular}{ccccc}
\hline \multicolumn{2}{c}{ Unbised Nei's Distance } & \multicolumn{2}{c}{ Differentiation Index (FST) } \\
\hline Genetic Groups & Exotic & Local & Exotic & Local \\
\hline Exotic & 0.000 & 0.887 & 0.000 & \\
Local & 0.120 & 1.000 & 0.024 & 0.000 \\
\hline
\end{tabular}

The AMOVA revealed $0 \%$ of variation among and within populations while $100 \%$ of the variation was within individual populations (Table 7).

Table 7. Analysis of molecular variance (AMOVA).

\begin{tabular}{cccccc}
\hline Source & df & SS & MS & Est. Var. & $\%$ \\
\hline Among populations & 1 & 2.069 & 2.069 & 0.009 & $0 \%$ \\
Among Individuals & 16 & 30.708 & 1.919 & 0.000 & $0 \%$ \\
Within Individuals & 18 & 60.000 & 3.333 & 3.333 & $100 \%$ \\
Total & 35 & 92.778 & & 3.343 & $100 \%$ \\
\hline Fixation Index (Fst) & & 0.004 & & \\
Number of migrants (NM) & & 69.95 & & \\
\hline
\end{tabular}

\subsection{Genetic Diversity and the Relationship among Spider Plant Accessions}

According to the Jaccard dissimilarity matrix, the 18 accessions were grouped into four clusters (Figure 2). Cluster one consisted of a single, local accession 'ML-3-KK', which showed no similarity with the rest of the accessions. Cluster two consisted of an exotic accession 'ML-SF-29' and five local accessions 'MP-B-3-CG', 'ML-13-SDM', 'MP-B-2-CG', 'ML-2-DD' and 'MP-B-4-CG', while the third cluster consisted of three accessions, two exotic accessions 'IP-3', 'TZ-1' and local accession 'ML-14-MAG'. The fourth cluster consisted of eight accessions, three exotic accessions 'GPS', 'PS', 'UG-SF-15' and five local accessions 'ML-12-TMP', ‘ML-5-TGM', 'MP-B-1-CG', 'ML-15-ITN', 'ML-6-BTK' (Figure 2).

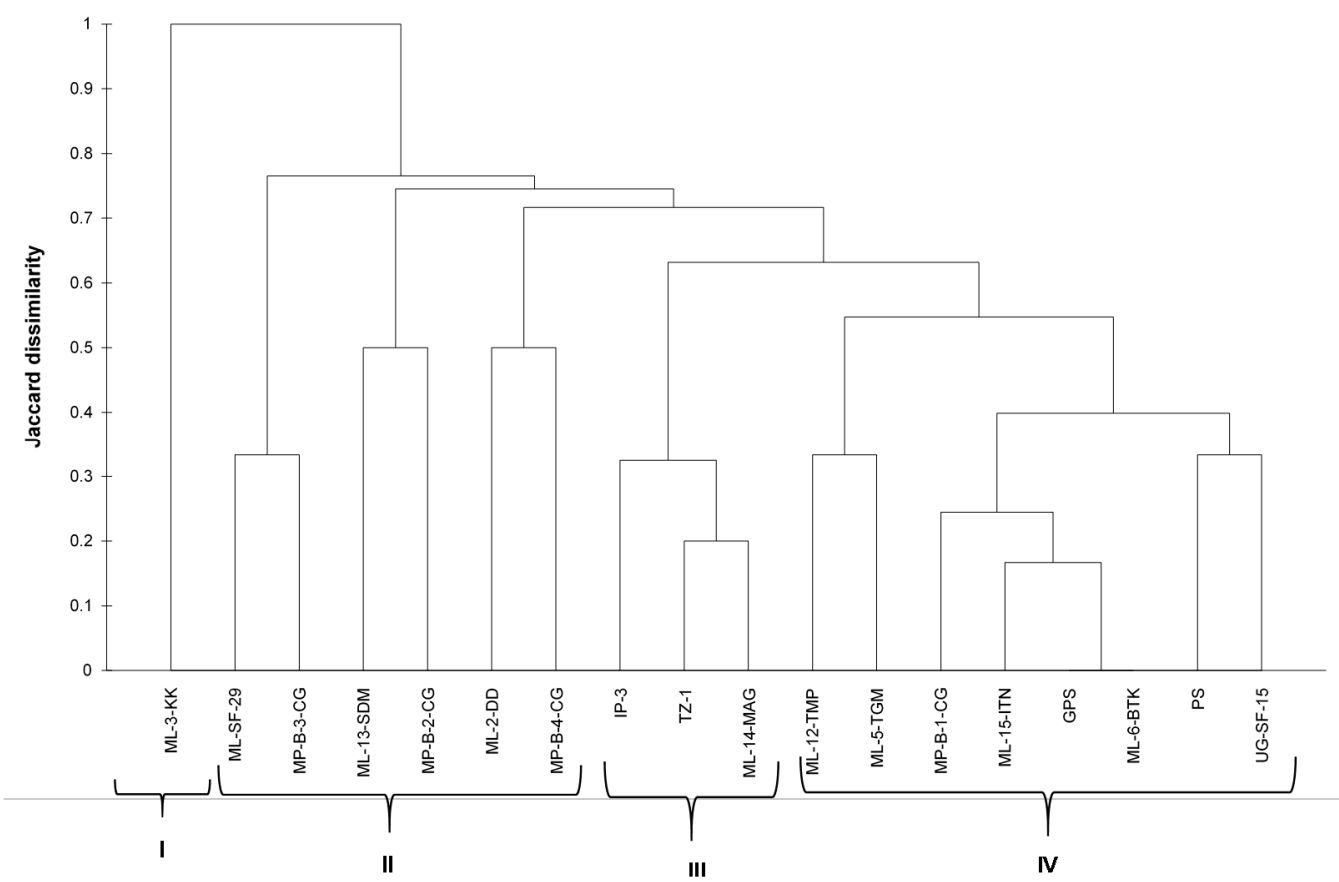

Figure 2. Dendrogram (unweighted pair group method with arithmetic mean) showing the relationship between 18 Spider plant accessions. 
The genetic relationship between local and exotic spider plant accessions was further assessed using the PCoA. Four groups were formed, with one accession 'ML-3-KK' forming a group alone. The PCoAs 1 and 2 accounted for $18.90 \%$ and $11.60 \%$ of the total variation, respectively (Figure 3). In addition, the PCoA revealed that the first three axes explained $41.56 \%$ of the total variation.

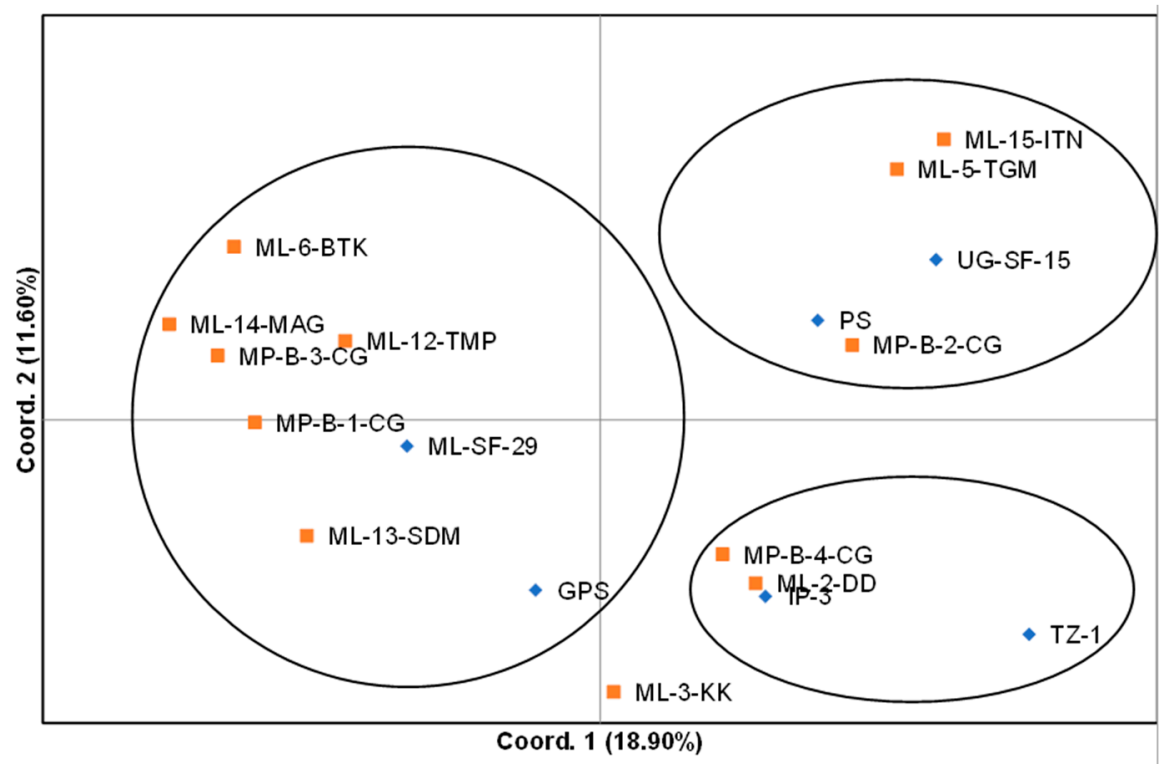

Figure 3. Principal coordinates analysis calculated from the pooled data of seven simple sequence repeat markers in 18 spider plant accessions.

\subsection{SSR Markers' Ability to Distinguish between the Exotic and Local Accessions}

Genetic variations were observed between local and exotic accessions. Different allele sizes were observed between local and exotic accessions of spider plant. The fingerprints of the local accessions 'ML-6-BTK' and 'MP-B-3-CG' were different from those of the exotic accession 'ML-SF-29' (Figure S1). The allele size among the local spider plant accessions ranged from 201-240 bp (Figure S1).

A total of 32 and 44 alleles were identified in exotic and local spider plant accessions respectively (Table 8). On average, there were less alleles (4.57) per locus in exotic accessions than in the local spider plant accessions (6.29). The number of alleles in the local and exotic accessions ranged from 3 to 8 and 3 to 10 alleles, respectively. The gene diversity in exotic accessions ranged from 0.57 in marker CG022 to 0.82 in marker CG001, while in the local accessions, it ranged from 0.62 in marker CG027 to 0.86 in marker CG001. The PIC value in exotic accessions ranged from 0.48 in marker CG022 to 0.80 in CG001, with an average of 0.62 per marker. In local spider plant accessions, the PIC value ranged from 0.55 in marker CG027 to 0.84 in marker CG001, with an average of 0.69 per marker.

A total of 19 rare alleles were detected in 11 spider plant accessions, with three occurring in two exotic accessions ('TZ1' and 'ML-SF-29') in markers CG001 and CG017, but 16 rare alleles were identified in the local spider plant accessions (Table 9). The frequency of these alleles ranged from 8 to $17 \%$ in the exotic accessions and 4 to $9 \%$ in the local accessions. Eight local spider plant accessions ('ML-2-DD', 'ML-5-TGM', 'ML-14-MAG', 'ML-3-KK', 'ML-12-TMP', 'ML-15-ITN', 'MP-B-1-CG', 'MP-B-2-CG' and 'MP-B-4-CG') showed rare alleles.

\subsection{Diversity between Accessions Based on the Stem Colour}

Different allele sizes were observed within the accessions based on the difference in the colour of stem (Figure S2). For instance, there were differences in the size of allele within the exotic accession 'GPS' between plants with a purple stem and a green stem. The fingerprints for the exotic accession 'GPS' with a purple stem differed from those with a green stem (Figure S2) suggesting that there was genetic variation within the accession. 
Table 8. Number of alleles, polymorphic information content found in the seven microsatellites between the exotic and local spider plant accessions.

\begin{tabular}{ccccccc}
\hline & \multicolumn{3}{c}{ Exotic $\mathbf{n}=\mathbf{6}$} & & \multicolumn{3}{c}{ Local $\mathbf{n}=\mathbf{1 2}$} \\
\hline SRR & Alleles & He & PIC & Alleles & He & PIC \\
\hline CG001 & 8 & 0.82 & 0.80 & 10 & 0.86 & 0.84 \\
CG017 & 6 & 0.75 & 0.72 & 8 & 0.82 & 0.78 \\
CG018 & 4 & 0.74 & 0.69 & 4 & 0.71 & 0.65 \\
CG022 & 3 & 0.57 & 0.48 & 6 & 0.70 & 0.65 \\
CG024 & 4 & 0.60 & 0.55 & 6 & 0.74 & 0.70 \\
CG027 & 3 & 0.61 & 0.54 & 3 & 0.62 & 0.55 \\
CG033 & 4 & 0.60 & 0.55 & 7 & 0.72 & 0.68 \\
\hline Total & 32 & - & - & 44 & - & - \\
Mean & 4.57 & 0.67 & 0.62 & 6.29 & 0.74 & 0.69 \\
SE & 0.69 & 0.04 & 0.04 & 0.89 & 0.03 & 0.04 \\
\hline
\end{tabular}

$\mathrm{He}=$ expected heterozygosity; $\mathrm{PIC}=$ polymorphic information index; $\mathrm{SE}=$ standard error.

Table 9. List of accessions with one or more private alleles.

\begin{tabular}{|c|c|c|c|c|c|c|c|c|}
\hline \multirow[b]{2}{*}{ SSR Maker } & \multicolumn{4}{|c|}{ Exotic } & \multicolumn{4}{|c|}{ Local } \\
\hline & Accession & $\begin{array}{c}\text { Number of } \\
\text { Private Allele }\end{array}$ & Allele & Frequency (\%) & Accession & $\begin{array}{l}\text { Number of } \\
\text { Private Allele }\end{array}$ & Allele & Frequency (\%) \\
\hline CG001 & TZ-1 & 1 & 194 & 8 & ML-2-DD, ML-5-TGM & 2 & $212,220,226$ & $5,5,5$ \\
\hline CG017 & $\begin{array}{l}\text { TZ-1, } \\
\text { ML-SF-29 }\end{array}$ & 2 & 245 & 17 & $\begin{array}{l}\text { ML-2-DD, ML-12-TMP, } \\
\text { ML-14-MAG, ML-3-KK }\end{array}$ & 4 & $199,231,240$ & $5,5,9$ \\
\hline CG022 & - & - & & & $\begin{array}{l}\text { ML-2-DD, ML-12-TMP, } \\
\text { ML-15-ITN, MP-B-2-CG }\end{array}$ & 4 & $212,217,231$ & $4,4,8$ \\
\hline CG024 & - & - & & & MP-B-2-CG, ML-15-ITN & 2 & 245,251 & 4,4 \\
\hline CG033 & - & - & & & $\begin{array}{l}\text { ML-14-MAG, ML-3-KK, } \\
\text { MP-B-1-CG, MP-B-4-CG }\end{array}$ & 4 & $197,202,217$ & $4,8,4$ \\
\hline Total & & 3 & & & & 16 & & \\
\hline
\end{tabular}

A total of 52 alleles were generated by SSR markers in accessions with a green stem with an average of 7 alleles per locus and 42 alleles in accessions with a purple stem, with an average of 6 alleles per locus (Table 10). The number of effective alleles ranged from 2.51 for marker CG027 to 8.58 for marker CG001 in accessions with green stems, while in those with purple stems the number of effective alleles ranged from 2.58 (CG022) to 7.60 (CG001). Shannon's Information Index ranged from 0.99 (CG027) to 2.39 (CG001) in phenotypes with a green stem. The expected heterozygosity revealed by the SSR marker ranged from 0.60 to 0.88 for accessions with a green stem, with an average of 0.75 , while the PIC value averaged at 0.71 (Table 10).

Table 10. Genetic diversity parameters generated by SSR markers between green and purple stem accessions.

\begin{tabular}{ccccccccccccccc}
\hline \multicolumn{1}{c}{ Green Stem (39) } & \multicolumn{4}{c}{ Purple Stem (28) } \\
\hline Locus & Na & Ne & I & Ho & He & F & PIC & Na & Ne & I & Ho & He & F & PIC \\
\hline CG001 & 15 & 8.58 & 2.39 & 1.00 & 0.88 & -0.13 & 0.87 & 12 & 7.60 & 2.21 & 1.00 & 0.87 & -0.15 & 0.86 \\
CG017 & 11 & 6.55 & 2.09 & 1.00 & 0.85 & -0.18 & 0.83 & 7 & 5.80 & 1.82 & 1.00 & 0.83 & -0.21 & 0.80 \\
CG018 & 4 & 3.62 & 1.33 & 1.00 & 0.72 & -0.38 & 0.67 & 4 & 3.54 & 1.32 & 1.00 & 0.72 & -0.39 & 0.67 \\
CG022 & 5 & 3.31 & 1.35 & 1.00 & 0.70 & -0.43 & 0.65 & 5 & 2.58 & 1.11 & 1.00 & 0.61 & -0.63 & 0.55 \\
CG024 & 6 & 3.89 & 1.48 & 1.00 & 0.74 & -0.35 & 0.69 & 5 & 3.79 & 1.41 & 1.00 & 0.74 & -0.36 & 0.69 \\
CG027 & 3 & 2.51 & 0.99 & 1.00 & 0.60 & -0.66 & 0.52 & 3 & 2.64 & 1.03 & 1.00 & 0.62 & -0.61 & 0.55 \\
CG033 & 8 & 4.18 & 1.69 & 1.00 & 0.76 & -0.31 & 0.73 & 6 & 4.52 & 1.63 & 1.00 & 0.78 & -0.28 & 0.75 \\
\hline Total & 52 & - & - & - & - & - & - & 42 & - & - & - & - & - & - \\
\hline Mean & 7 & 4.66 & 1.62 & 1.00 & 0.75 & -0.35 & 0.71 & 6.00 & 4.35 & 1.51 & 1.00 & 0.74 & -0.38 & 0.70 \\
SE & 1.62 & 0.81 & 0.18 & 0.00 & 0.04 & 0.07 & 0.04 & 1.11 & 0.69 & 0.16 & 0.00 & 0.04 & 0.07 & 0.04 \\
\hline
\end{tabular}

$\mathrm{Na}=$ number of alleles per locus, $\mathrm{Ne}=$ number of effective alleles per locus; I = Shannon's information index; Ho = observed heterozygosity; $\mathrm{He}=$ expected heterozygosity; F = fixation index; PIC = polymorphic information index; $\mathrm{SE}=$ standard error. 


\section{Discussion}

This study found variation in the number of alleles generated per locus with at least three alleles per locus. This was consistent with previous reports in similar studies in which the number of alleles per locus ranged from 3-7 in 30 entries of spider plant [27]. In addition, some of the informative SSR markers (for instance CG001), were able to distinguish between the local and exotic accessions. Such markers could be useful in cultivar identification, as demonstrated previously in several crop species including potato [35] and watermelon [36], among others. The high polymorphism observed in the study suggested that the markers used in this study were effective in discriminating between the spider plant accessions. The relatively high average Shannon's information index (1.52) which was observed, suggested a high discriminatory capacity of the markers that were used in this study. Many factors affect PIC values, including the breeding method of the species, the genetic diversity in the collection, the size of the population, the sensitivity of the method used for genotyping, and locations of primers in the genome [37].

The number of spider plant individuals was limited partly because the germplasm collection of this leafy vegetable is still at a preliminary phase in the envisaged breeding program of this crop. Currently, spider plant is considered largely as an orphan (or neglected) crop which is collected from the wild [38]. Only a limited number of local accessions with distinct morphological characters was available for this initial study, but future germplasm collection expeditions intend to include more individuals from each local accession in order to map out a more robust population genetic structure of the local spider plant. Moreover, smaller sample sizes of accessions (less than 18) were used and reported previously in similar genetic diversity studies using SSR markers in several crop species, including maize [39] and wheat [40]. The molecular markers that were used in this study were deemed sufficient for a small sample size and were consistent with the approaches that were employed in previous similar work. For instance, in a similar study aimed at evaluating the genetic diversity among 25 Tunisian pear (Pyrus communis) cultivars, seven SSR markers were used successfully to amplify at least 36 fragments, with a mean expected heterozygosity averaging 0.71 - thus suggesting a high level of genetic diversity in germplasm [41]. In another similar study involving red clover (Trifolium pratense L.), over seven SSR loci produced a high genetic diversity, with a mean expected heterozygosity of 0.86 [42].

Simple sequence repeats with high PIC values also showed a high number of effective alleles per locus, indicating a high marker ability for genetic analysis among spider plant accessions. The similarity between the local and exotic accessions was demonstrated by a negative fixation index observed for all the markers. Moreover, the AMOVA showed that the total variation $(100 \%)$ was accounted for within individual variations. The high variation observed within individual accessions may be explained by the high heterozygosity observed in this study and the lack of differentiation between the exotic and local spider plant accessions, since the exotic accessions are gene bank accessions and the local spider plant accessions were collected from the wild. Furthermore, the low differentiation between the accessions may be attributed to a lack of isolation during seed multiplication in the field, since the spider plant is a cross-pollinated species. Another factor that might have contributed to the low differentiation between the exotic and local spider plant accessions is the limited number of accessions and markers used in this study. The Nei's diversity index in this study was high when compared with previous reports in which the index ranged from 0.13-0.77 [27] and 0.3-0.6 [25]. Limited gene flow exchange is indicated by low Nm values [43]. In this study, high Nm values were observed, suggesting high genetic exchange or gene flow.

A high average heterozygosity value was observed in the local spider plant accessions when compared to the exotic accessions, meaning that the former accessions were more diverse. In addition, the low heterozygosity observed in exotic germplasm could be attributed to the low number of accessions that were used in the study. The two populations presented differences in the loci with concern to the number of private alleles observed. 
Local spider plant accessions had a wide range of loci with private alleles, probably due to the relatively larger population that was used in comparison with the exotic population. Furthermore, the local spider plant accessions were more genetically diverse with concern to more private alleles. Such alleles provide useful information on rare variability in certain loci and identify diverse accessions that could be used as parental lines in breeding programmes to maximize the allele richness in the population.

The hierarchal clustering grouped the spider plant accessions into four distinct groups, with no clear distinction between exotic and local accessions. However, variation between individual accessions were observed. The results of the cluster analysis and PCoA were consistent with each other in grouping the 18 spider plant accessions into four groups, with 'ML-3-KK' on its own. This suggested that this accession was superior among the set of accessions that were evaluated in the study. The results from this study did not show a clear differentiation between the green and purple spider plant morphotypes. These results are different to those reported by [25] who reported a clear difference between four morphotypes from Kenya using RAPD markers.

Supplementary Materials: The following are available online at https://www.mdpi.com/article/ 10.3390/agronomy11112206/s1, Figure S1: GENEMAPPER output of microsatellite marker CG017 for local accession 'ML-6-BTK' and 'MP-B-3-CG'and exotic accession 'ML-SF-29'. Figure S2: GENEMAPPER output of microsatellite marker CG017 for exotic spider plant accession 'GPS', (A) purple stem and (B) green stem.

Author Contributions: Conceptualization, F.T. and E.T.G.; Investigation, S.S.S. and F.T.; formal analysis, T.K., S.S.S. and F.T.; writing — original draft preparation, F.T.; writing—review and editing, E.T.G., F.T., T.K., S.S.S. and G.R.A.M. All authors have read and agreed to the published version of the manuscript.

Funding: This research was funded partly by the National Research Foundation (Thuthuka Grant number TTK160510164545.

Institutional Review Board Statement: Not applicable.

Informed Consent Statement: Not applicable.

Data Availability Statement: The data presented in this study are available on request from the corresponding author.

Acknowledgments: The authors would like to acknowledge the World Vegetable Centre (Arusha, Tanzania) for part of the Spider plant germplasm that was used in this study. We also gratefully acknowledge the assistance with the laboratory and microsatellite analysis at the central analytical laboratory (CAF) by Kenneth Tobutt.

Conflicts of Interest: The authors declare no conflict of interest.

\section{References}

1. Omondi, E.O.; Engels, C.; Nambafu, G.; Schreiner, M.; Neugart, S.; Abukutsa-Onyango, M.; Winkelmann, T. Nutritional compound analysis and morphological characterization of spider plant (Cleome gynandra)—An African indigenous leafy vegetable. Food Res. Int. 2017, 100, 284-295. [CrossRef]

2. Njume, C.; Goduka, N.I.; George, G. Indigenous leafy vegetables (imifino, morogo, muhuro) in South Africa: A rich and unexplored source of nutrients and antioxidants. Afr. J. Biotechnol. 2014, 13, 1933-1942. [CrossRef]

3. van Jaarsveld, P.; Faber, M.; van Heerden, I.; Wenhold, F.; van Rensburg, W.J.; van Averbeke, W. Nutrient content of eight African leafy vegetables and their potential contribution to dietary reference intakes. J. Food Compos. Anal. 2014, 33, 77-84. [CrossRef]

4. Onyango, C.M.; Kunyanga, C.N.; Ontita, E.G.; Narla, R.D.; Kimenju, J.W. Production, utilization and indigenous knowledge of spider plant in Kenya. Afr. Crop. Sci. Proc. 2013, 11, 925-930.

5. Ng'etich, O.K.; Aguyoh, J.N.; Ogweno, J.O. Growth, yield and physiological responses of spider plant (Cleome gynandra L.) to calcium ammonium nitrate rates. Int. J. Agron. Plant. Prod. 2012, 3, 346-355.

6. Mauyo, L.W.; Anjichi, V.E.; Wambugu, G.W.; Omunyini, M.E. Effect of nitrogen fertilizer levels on fresh leaf yield of spider plant (Cleome gynandra L.) in Western Kenya. Sci. Res. Essays. 2008, 3, 240-244.

7. van Rensburg, W.S.J.; van Averbeke, W.; Slabbert, R.; Faber, M.; van Jaarsveld, P.; van Heerden, I.; Wenhold, F.; Oelofse, A. African leafy vegetable in South Africa. Water SA 2007, 33, 317-326. [CrossRef] 
8. Onyango, C.M.; Onwonga, R.N.; Kimenju, J.W. Assessment of Spider plant (Cleome gynandra L.) germplasm for agronomic traits in vegetable and seed production: A greenhouse Study. Am. J. Exp. Agric. 2016, 10, 1-10. [CrossRef]

9. Chweya, J.A.; Mnzava, N.A. Promoting the Conservation and Use of Underutilized and Neglected Crops. 11. Cat's Whiskers; IPGRI: Rome, Italy, 1997.

10. Omondi, E.O.; Debener, T.; Linde, M.; Abukutsa-Onyango, M.; Dinssa, F.F.; Winkelmann, T. Molecular makers for genetic diversity studies in African leafy vegetables. Adv. Biosci. Biotechnol. 2016, 7, 188-197. [CrossRef]

11. Bhandari, H.R.; Bhanu, A.N.; Srivastava, K.; Singh, M.N.; Shreya, H.A. Assessment of Genetic Diversity in Crop Plants-An Overview. Adv. Plants Agric. Res. 2017, 7, 279-286.

12. Govindaraj, M.; Vetriventhan, M.; Srinivasan, M. Importance of genetic diversity assessment in crop plants and its recent advances: An overview of its analytical perspectives. Genet. Res. Int. 2015, 2015, 431487. [CrossRef] [PubMed]

13. Mondini, L.; Noorani, A.; Pagnotta, M.A. Assessing plant genetic diversity by molecular tools. Divers. 2009, 1, 19-35. [CrossRef]

14. Wasonga, D.O.; Ambuko, J.L.; Chemining'wa, G.N.; Odeny, D.A.; Crampton, B.G. Morphological Characterization and Selection of Spider Plant (Cleome Gynandra) Accessions from Kenya and South Africa. Asian J. Agric. Sci. 2015, 7, 36-44. [CrossRef]

15. Masuka, A.; Goss, M.; Mazarura, U. Morphological characterization of four selected Spider plant (Cleome gynandra L.) morphs from Zimbabwe and Kenya. Asian J. Agric. Rural Dev. 2012, 2, 646-657.

16. K'Opondo, F.B.O. Morphological characterization of selected Cleome gynandra L. types from western Kenya. Ann. Biol. Res. 2011, 2, 54-64.

17. Glaszmann, J.C.; Kilian, B.; Upadhyaya, H.D.; Varshney, R.K. Accessing genetic diversity for crop improvement. Curr. Opin. Plant. Biol. 2010, 13, 167-173. [CrossRef]

18. Mafakheri, K.; Bihamta, M.R.; Abbasi, A.R. Assessment of genetic diversity in cowpea (Vigna unguiculata L.) germplasm using morphological and molecular characterization. Cogent Food Agric. 2017, 3, 1327092. [CrossRef]

19. Poczai, P.; Mátyás, K.; Taller, J.; Szabó, I. Study of the origin of the rarely cultivated edible Solanum species: Morphological and molecular data. Biol. Plant. 2010, 54, 543-546. [CrossRef]

20. Tony-Odigie, A.E.; Adekoya, K.O.; Makinde, S.C.O.; Oboh, B.O.; Ogunkanmi, L.A.; Fowora, M.A. Assessment of Genetic Interspecies Relationships among Five Selected Amaranthus Species Using Phenotypic and RAPD Markers. Int. J. Bot. 2012, 8 , 145-152. [CrossRef]

21. Kumar, S.; Parekh, M.J.; Fougat, R.S.; Patel, S.K.; Patel, C.B.; Kumar, M.; Patel, B.R. Assessment of genetic diversity among okra genotypes using SSR markers. J. Plant. Biochem. Biotechnol. 2017, 26, 172-178. [CrossRef]

22. Yuan, C.Y.; Wang, P.; Chen, P.P.; Xiao, W.J.; Zhang, C.; Hu, S.; Zhou, P.; Chang, H.P.; He, Z.; Hu, R.; et al. Genetic diversity revealed by morphological traits and ISSR markers in 48 Okras (Abelmoschus escullentus L.). Physiol. Mol. Biol. Plants 2015, 21, 359-364. [CrossRef] [PubMed]

23. Kaur, K.; Pathak, M.; Kaur, S.; Pathak, D.; Chawla, N. Assessment of morphological and molecular diversity among okra [Abelmoschus esculentus (L.) Moench.] Germplasm. Afr. J. Biotechnol. 2013, 12, 3160-3170.

24. Gwata, E.T.; Wofford, D.S. Potential of RAPD analysis of the promiscuous nodulation trait in soybean (Glycine max L). Biol. Fertil. Soils. 2013, 49, 241-244. [CrossRef]

25. K'Opondo, F.B.O.; van Rheenen, H.A.; Muasya, R.M. Assessment of genetic variation of selected Spider plant (Cleome gynandra L.) morphotypes from Western Kenya. Afr. J. Biotechnol. 2009, 8, 4325-4332.

26. Kiebre, Z.; Bationo/Kando, P.; Nanema, K.R.; Sawadogo, B.; Kiebre, M.; Traore, R.E.; Sawadogo, M.; Zongo, J.-D. Genetic Diversity of Spider Plant (Cleome gynandra L.) of Burkina Faso Using ISSRs Markers. Int. J. Curr. Res. Biosci. Plant. Biol. $2017,4,44-51$.

27. Omondi, E.O.; Debener, T.; Linde, M.; Abukutsa-Onyango, M.; Dinssa, F.F.; Winkelmann, T. Mating biology, nuclear DNA content and genetic diversity in spider plant (Cleome gynandra) germplasm from various African countries. Plant. Breed. 2017, 136, 578-589. [CrossRef]

28. Sahu, S.K.; Thangaraj, M.; Kathiresan, K. DNA extraction protocol for plants with high levels of secondary metabolites and polysaccharides without using liquid nitrogen and phenol. Int. Sch. Res. Net. 2012, 2012, 205049. [CrossRef]

29. Lade, B.D.; Patil, A.S.; Paikrao, H.M. Efficient genomic DNA extraction protocol from medicinal rich Passiflora foetida containing high level of polysaccharide and polyphenol. SpringerPlus 2014, 3, 457. [CrossRef] [PubMed]

30. Schuelke, M. An economic method for the fluorescent labeling of PCR fragments. Nat. Biotechnol. 2000, 18, 233-234. [CrossRef]

31. Peakall, R.; Smouse, P. GenAIEx V5: Genetic Analysis in Excel. Populations Genetic Software for Teaching and Research. Bioinformatics 2012, 28, 2537-2539. [CrossRef]

32. Nei, M. Analysis of gene diversity in subdivided populations. Proc. Natl. Acad. Sci. USA 1973, 70, 3321-3323. [CrossRef]

33. Bińkowski, J.; Miks, S. Gene-Calc [Computer Software]. 2018. Available online: www.gene-calc.pl (accessed on 14 June 2021).

34. Abdelaziz, M.S.; Medraoui, L.; Alami, M.; Pakhrou, O.; Makkaoui, M.; Boukhary, A.O.M.S.; Filali-Maltouf, A. Inter simple sequence repeat markers to assess genetic diversity of the desert date (Balanites aegyptiaca Del.) for Sahelian ecosystem restoration. Sci. Rep. 2020, 10, 14948. [CrossRef]

35. Moisan-Thiery, M.; Marhadour, S.; Kerlan, M.C.; Dessenne, N.; Perramant, M.; Gokelaere, T.; Le Hingrat, Y. Potato cultivar identification using simple sequence repeats markers (SSR). Potato Res. 2005, 48, 191-200. [CrossRef]

36. Nguyen, N.N.; Kwon, Y.S.; Park, J.R.; Sim, S.C. Development of a core set of SSR markers for cultivar identification and seed purity tests in oriental melon (Cucumis melo L. var. makuwa). Hortic. Sci. Technol. 2019, 37, 119-129. 
37. Singh, N.; Choudhury, D.R.; Singh, A.K.; Kumar, S.; Srinivasan, K.; Tyagi, R.K.; Singh, N.K.; Singh, R. Comparison of SSR and SNP markers in estimation of genetic diversity and population structure of Indian rice varieties. PLoS ONE 2013, 8, e84136.

38. Thovhogi, F.; Gwata, E.T.; Mchau, G.R.A.; Ntushelo, N. Perceptions of end-users in Limpopo Province (South Africa) about the spider plant (Cleome gynandra L.). Genet. Resour. Crop. Evol. 2021, 68, 605-614. [CrossRef]

39. Kumari, A.; Sinha, S.; Rashmi, K.; Mandal, S.S.; Sahay, S. Genetic diversity analysis in maize (Zea mays L.) using SSR markers. J. Pharmacogn. Phytochem. 2018, SP1, 1116-1120.

40. Haque, M.S.; Saha, N.R.; Islam, M.T.; Kwon, S.J.; Roy, S.K.; Woo, S.H. Screening for drought tolerance in wheat genotypes by morphological and SSR markers. J. Crop. Sci. Biotechnol. 2021, 24, 27-39. [CrossRef]

41. Brini, W.; Mars, M.; Hormaza, J.I. Genetic diversity in local Tunisian pears (Pyrus communis L.) studied with SSR markers. Sci. Hortic. 2008, 115, 337-341. [CrossRef]

42. Dias, P.M.B.; Julier, B.; Sampoux, J.P.; Barre, P.; Dall'Agnol, M. Genetic diversity in red clover (Trifolium pratense L.) revealed by morphological and microsatellite (SSR) markers. Euphytica 2008, 160, 189-205. [CrossRef]

43. Wright, S. The interpretation of population structure by F-statistics with special regard to systems of mating. Evolution 1965, 19, 395-420. [CrossRef] 